\title{
Tuning COCOMO-II for Software Process Improvement: A Tool Based Approach
}

\author{
SYEDA UMEMA HANI*, ABU TURAB ALAM**, AND ABDUL BASIT SHAIKH* \\ RECEIVED ON 20.05.2015 ACCEPTED ON 16.09.2015
}

\begin{abstract}
In order to compete in the international software development market the software organizations have to adopt internationally accepted software practices i.e. standard like ISO (International Standard Organization) or CMMI (Capability Maturity Model Integration) in spite of having scarce resources and tools. The aim of this study is to develop a tool which could be used to present an actual picture of Software Process Improvement benefits in front of the software development companies. However, there are few tools available to assist in making predictions, they are too expensive and could not cover dataset that reflect the cultural behavior of organizations for software development in developing countries. In extension to our previously done research reported elsewhere for Pakistani software development organizations which has quantified benefits of SDPI (Software Development Process Improvement), this research has used sixty-two datasets from three different software development organizations against the set of metrics used in COCOMO-II (Constructive Cost Model 2000). It derived a verifiable equation for calculating ISF (Ideal Scale Factor) and tuned the COCOMO-II model to bring prediction capability for SDPI (benefit measurement classes) such as ESCP (Effort, Schedule, Cost, and Productivity). This research has contributed towards software industry by giving a reliable and low-cost mechanism for generating prediction models with high prediction accuracy. Hopefully, this study will help software organizations to use this tool not only to predict ESCP but also to predict an exact impact of SDPI.
\end{abstract}

Key Words: Software Process Improvement, SPI Benefits, Capability Maturity Model Integration, COCOMO, Process Performance, Process Performance Models PPM, Metrics.

\section{INTRODUCTION}

$\mathrm{T}$ here exists a strong relation between the process and its outcome i.e. Product. It has been observed that the majority of organizations are not following a systematic approach due to the scarcity of resources and are required to deliver quality products to the market within short time spans. Due to the lack of process infrastructure, like requirement management, change management, supplier agreement management, and other practices, as a consequence, organizations go through extensive modifications to working practices, which result in unhappy customers, poor quality product, lots of rework, cost overrun and loss in market share [1-2]. Various empirical studies have

\footnotetext{
* Graduate School of Engineering Sciences \& Information Technology, Hamdard University, Karachi.

** Department of Computer Science, Institute of Business Management, Karachi.
}

Mehran University Research Journal of Engineering \& Technology, Volume 35, No. 4, October, 2016 [p-ISSN: 0254-7821, e-ISSN: 2413-7219] 
also been conducted to confirm the link between higher CMM levels and higher product quality. Thus, the improvement of software product quality and software productivity requires understanding of the software development process's capability i.e. the maturity of that company's software development process [3], which is known in a form of different models. These models include CMMI and ISO/IEC 15504 (a standard for software process assessment agreed by ISO and the International Electrotechnical Commission), whereas ISO/IEC 15504 is an international standard for determining process capability and the CMMI is the most popular model which is in compliant with the ISO/IEC 1504 standard [4]. The benefits of these approaches are not always natural and need more industrybased studies [5]. Recently, the authors have done research [6] in this regard, in which benefits have been empirically identified for the Pakistani working environment.

One major problem which the software industry is currently facing in SDPI adaptation is the shortage of proper tools [79]. In spite of having some models or tools available which could be directly or indirectly used for benefit measurement and prediction purpose like COSTAR, SEER, SLIM, CostXpert, KnowledgePlan, and Software Risk Master [10]. But none of the tools are cost effective and reflects cultural or environmental behavior for the developing countries. The developing countries are involved in outsourcing with the world's technologically strong countries, but they are not evident enough to gain client trust, and their adopted SDPI's effects are debatable.

Therefore, this research compensates the raised needs of developing persuasive cost and benefits justification in a form of tool for its adoption. The main contribution of this study for the body of knowledge is to present a prediction model for SDPI benefit measurement classes ESCP. This tool could be used by multiple organizations to predict the impact of different SDPI level wise ESCP values. The model comes under the category of PPM Process Performance Model [11] and also could be utilized for measuring organization's business performance measurement and prediction [12].
Fig. 1 presents overall research flow and it shows that ESCP related data has been collected from organizations which have been appraised to different SDPI levels. A questionnaire was designed and sixty-two data sets have been collected from three different CMMI appraised organizations against the set of metrics used in COCOMO-II [13]. COCOMO-II Post Architecture model is tuned to bring prediction capability for SDPI "benefit measurement classes" such as Effort, Schedule, Cost, and Productivity using ISF (Ideal Scale Factor) analysis. Model prediction accuracy has been checked using the MMRE (Mean Magnitude of Relative Error) and PRED (30) measures for comparing the ESCP values calculated from old values of PMAT (Process Maturity) scaling with the ESCP values calculated from ISFPMAT values that are calculated in this research. If the newly tuned PMAT variable of this research gives better prediction ability than the COCOMO-II model's PMAT variable, only then, COCOMO-II model with new PMAT variable will be used for the prediction of ESCP metrics. The model was tuned for reflecting CMMI impact in Pakistani software development environment. The new model of this research has verified the substantial increase or decrease in ESCP values as calculated in our previous study [6].

The composition of this paper is as follows: Section 1 covers introduction, Section 2 discusses literature review including problems in model selection, Section 3 discusses research methodology i.e. hypotheses statement, research question, and its investigation, data collection procedure and questionnaire analysis. Data analysis (ISF Analysis) is given in Section 4. Section 5 covers threats to validity, whereas Section 6 covers discussion of results (model accuracy with ISF results). Section 7 and 8 covers conclusion and future work.

\section{LITERATURE REVIEW}

Different SDPI approaches are in use by the software industry to improve software quality, productivity and software development capability using process assessmentbased approaches [14]. Using different assessment approaches, the process capability and maturity of an

Mehran University Research Journal of Engineering \& Technology, Volume 35, No. 4, October, 2016 [p-ISSN: 0254-7821, e-ISSN: 2413-7219] 
organization could be identified through which the process's strengths, weaknesses, and risks are known; therefore their prevention is possible [15]. These approaches may involve different software process models, and estimation models like Function Point FP, Constructive Cost Models etc. The first challenge of this research was to select a prediction method which could be used with the non-normal dataset and which could gain public trust. During the selection of generic metrics, a detailed literature review has been performed to select popular recommendations related to the use of metrics in the field of "Quality and Process Improvement". This section discusses a few most relevant references from a literature review. Section 2.1 covers a detailed literature review on the model selection for SPI benefits prediction.

\subsection{Prediction Model Selection}

Different models are in use by the industry for cost-benefit measurement and prediction. Through literature review the similarities have been determined between different software development prediction models [16-17] and SDPI benefit measurement classes like ESCP, so that these similarities could be leveraged with the SDPI benefit prediction models. A survey based research [18] for selecting a suitable model for research purpose highlights that plenty of commercial tools were available but, the COCOMO-II model has been a primary attraction because of its fully available internal equations, and parameter values. Furthermore, there is another research published which has concluded that COCOMO-II Post Architecture model is most accurate model among different COCOMO models and gives accuracy of $\operatorname{PRED}(30 \%)=70 \%$ of times [19].

\subsection{Selected Prediction Model and CMMI's Benefit Prediction}

During the literature review, an industrial study [20] (SD process Canada 2004) presents an overview of CMMI-DEV software process improvement framework and the involvement of COCOMO based estimation processes in it. The study mentions that COCOMO model is helpful in improving the overall consistency of the organizational process in estimating project resources. By using it, a

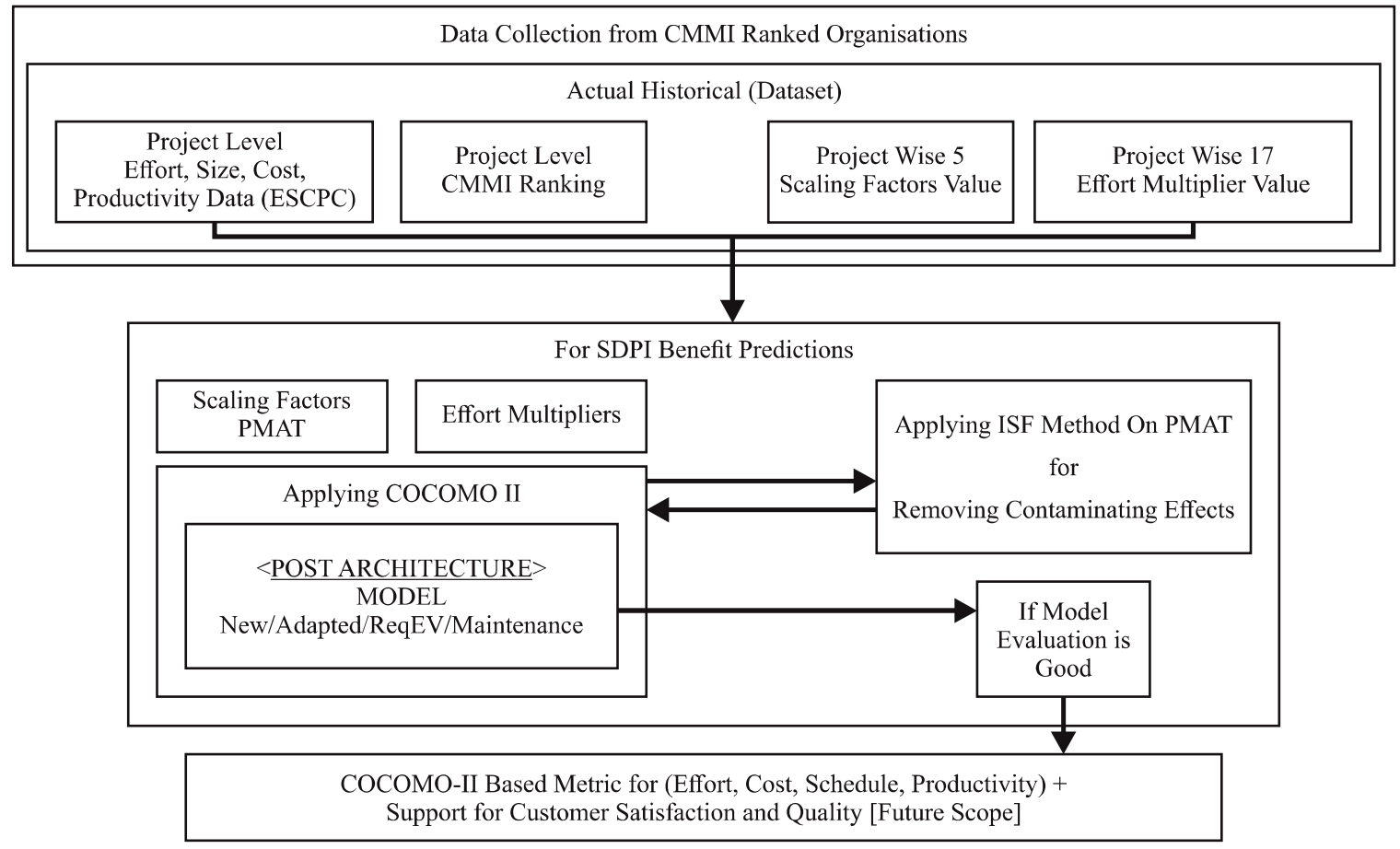

FIG. 1. RESEARCH FLOW

Mehran University Research Journal of Engineering \& Technology, Volume 35, No. 4, October, 2016 [p-ISSN: 0254-7821, e-ISSN: 2413-7219] 
historical data repository is properly maintained which is utilized in other high maturity process areas. When an organization reaches Maturity level 4 it uses the historical data repository containing the resource estimates for constructing PPM (Process Performance Models). Maturity level 5 organizations are challenged by changing business environments to reduce product costs and schedules. The resource estimates provided by COCOMO algorithms provide an aid to quantitatively manage the process variance to bring improvement. It is used to increase the efficiency of data collection and verification activities in SCAMPI appraisals. The CMMI process areas which are dependent on COCOMO model also include Organizational Process Definition, Organizational Process Focus, Organizational Process Performance, etc.

The COCOMO's Post Architecture model is a detailed one and is used once the software lifecycle architecture is defined and validated. The model predicts Effort in PM (Person Months) and schedule. The model takes size as an input and executes on a set of 17 effort multipliers and a set of 5 scaling factors. The model has the form:

$\operatorname{Effort}(\mathrm{PM})=2.94 * \operatorname{Size}^{\mathrm{E}} *\left(\Pi_{\mathrm{i}=1-17}\right.$ Effort Multiplier $)$

where $\mathrm{E}=\left(0.91+0.01 *{ }_{\mathrm{j}=1-5}\right.$ Scaling Factor $)$

The value of SF Scale Factors in the equation is adjusted which causes an exponential variation on a project's effort or productivity variation. The EM (Effort Multipliers) are the project controllable knobs that represent high payoff areas to emphasize in a software productivity improvement activity. The rating scale for both SF and EM are scaled in between five levels from very low to Extra high.

\subsection{Prediction Model Tuning}

There exist numerous studies on calibrations conducted on COCOMO-II [21-24]. Research [22] has been done that describes the calibration of the COCOMO-II Post Architecture model using Bayesian approach. This research has claimed to give significantly better results than the multiple regression approach. Another reference [25] discusses an IEM (Ideal Effort Multiplier) method and considers it as the simplest way to analyze the correlation between the effect of COCOMO effort multipliers and the actual data from software projects by mapping Project productivity and the cost driver on the graph. But, the results may not be very clear due to the reason that the effects of other cost drivers get mixed in with the effort multipliers. For example, some of the projects in the COCOMO database with very low required reliability had relatively low productivity because they were performed with very lowrated analysts and programmers, and with very low use of modern programming practices. Therefore, for getting a clearer impact of a cost driver on development productivity, there is a need to eliminate the foul effects of other cost driver attributes as much as possible. The best way we found to normalizing these other effects is to compute a quantity called the IEM for the project wise cost-driver combination. Using it we can get a clearer assessment of cost driver's effect on the project and a comparison of that effort with the COCOMO multiplier for the cost driver.

The results of this analysis might show a strong correlation between the COCOMO effort multipliers (the white circles) and the project's IEM for the selected attribute, as will be evidenced by the median values of the project data (the arrows) for each selected attribute rating. The correlation might not perfect, but it gives us reasonable confidence that the COCOMO effort multipliers are approximately the right magnitude and going in the right direction as a function of cost driver attribute rating. The results for any of the cost driver attribute could be something like as shown in Fig. 2. That is all the data points (black circles) would lie within the circle(White).

Few years back, a team of researchers in a study [26] used the same approach for driving new PMAT values in COCOMO-II and named it Ideal Scale Factor method. Using a PRED (30) measure the study claims that it shows a better estimates as compared with the COCOMO-II model estimates.

Mehran University Research Journal of Engineering \& Technology, Volume 35, No. 4, October, 2016 [p-ISSN: 0254-7821, e-ISSN: 2413-7219] 


\section{METHODOLOGY}

\subsection{Research Question and Hypotheses}

The primary RQ (Research Questions) of this research are as follows:

RQ-1: Does the prediction of updated COCOMO model reflects more accurate Predictions for ESCP values than the original COCOMO model being upgraded for CMMI, which makes it suitable for usage in Pakistani software industry.

RQ-2: Does the prediction accuracy of COCOMO model tuned using IEM method is not better than the prediction accuracy of COCOMO model tuned using ISF method of this research.

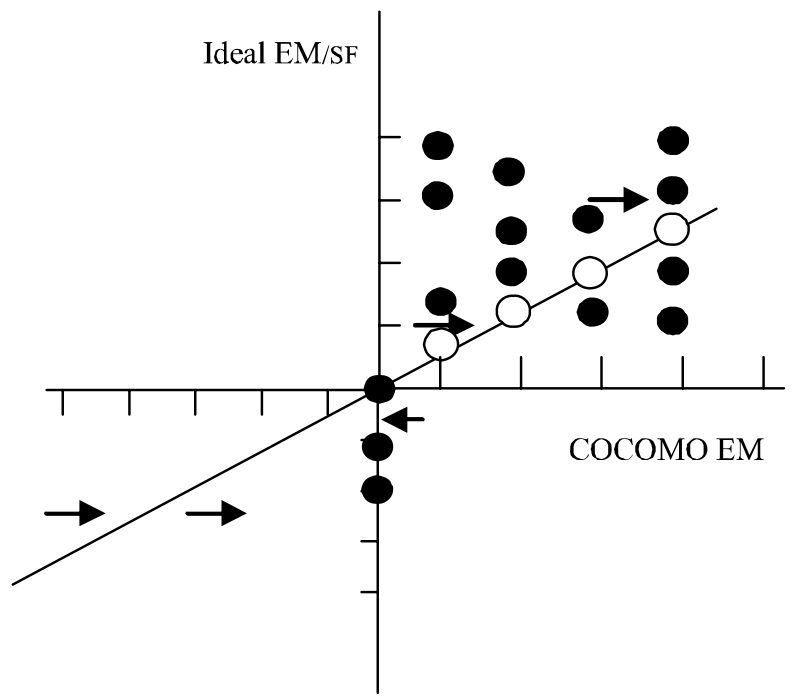

FIG. 2. GRAPHS BETWEEN ISF AND COCOMO SCALING FACTOR VALUES FOR PMAT

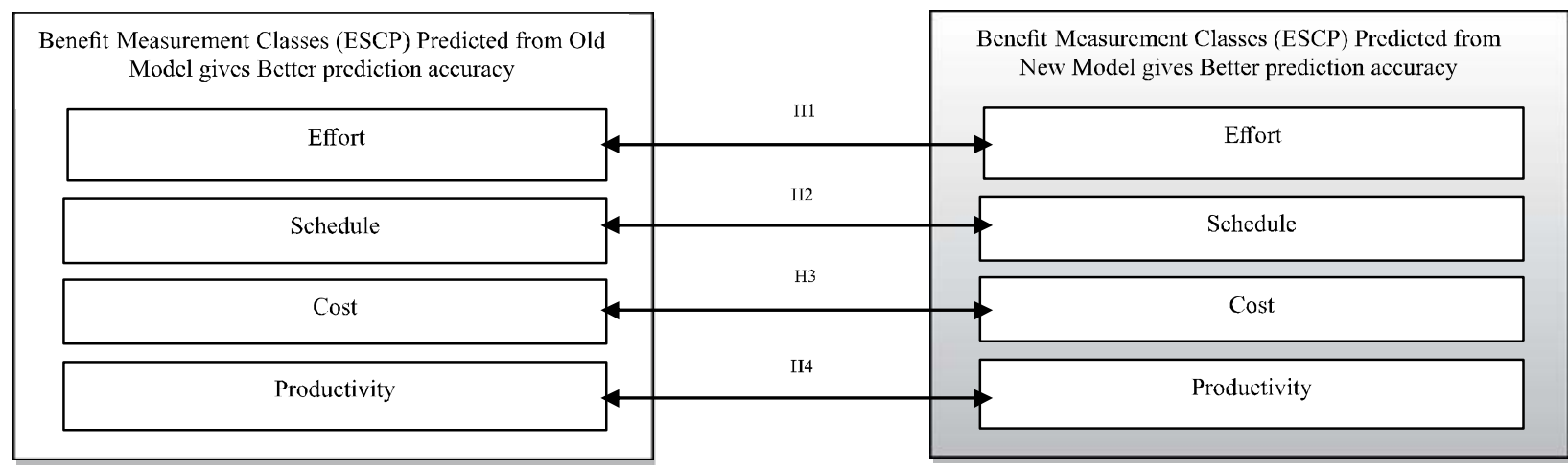

FIG. 3. RESEARCH MODEL AND HYPOTHESES INVESTIGATION, PARTICIPANT ORGANIZATIONS AND PRIVACY CONCERNS
To investigate the above RQ-1, a more detailed set of four hypotheses are defined see Section 4.4 for checking results of these hypotheses. The following are the posted hypotheses:

H1: Increasing levels of SDPI gives more accurate results for Effort estimation in this research's model than original COCOMO model.

(2) H2: Increasing levels of SDPI gives more accurate results for Schedule estimation in this research's model than original COCOMO model.

(3) H3: Increasing levels of SDPI gives more accurate results for Cost estimation in this research's model than original COCOMO model.

(4) H4: Increasing levels of SDPI gives more accurate results for Productivity estimation in this research's model than original COCOMO model.

Fig. 3 presents the research model with the associated hypotheses. The historical data has been collected from three formally CMMI appraised organizations and it is collected only for those projects which were developed within the validity period of their organization's adopted SDPI standard.

With the permission of company CEOs, the quality managers were assigned to us for data collection. The names of participant organizations were kept hidden in respect to data protection policy and project numbers were allocated to each

Mehran University Research Journal of Engineering \& Technology, Volume 35, No. 4, October, 2016 [p-ISSN: 0254-7821, e-ISSN: 2413-7219] 
participant organization. Table 1 shows the context of the three organization's key data i.e. the studied company's employed SPI initiatives and/or maturity levels, and its mapping with the studied projects in this research. For example, a CMMI maturity level 3 company (C) has contributed its five data set out of which four were used in this research. For the interpretation of SDPI levels, see Section 3.2.2 for details.

\subsection{Questionnaire and Data Collection}

For data collection, a questionnaire was designed collecting primary research data from multiple organizations. The "phone interview" was used as a method of collecting data. It is considered as high in terms of respondent's motivation and low in interview bias as discussed in reference [27]. It's every single copy was applicable on every individual organization which has reported multiple data sets. In this research, the data has been collected over a 6 month period in early 2011. Survey participation requests were sent through email. A total of 24 questionnaires were delivered to respondents through email out of which 4 were returned, yield a response rate of $16 \%$. One questionnaire was eliminated due to missing data. Three were analyzed which made the response rate of $(80 \%)$. The sample consisted of 62 data sets collected from 3 organizations which are comparable to data set used in studies [16,28-30] and is reasonably large as compared with study [26]. Projects were related to Healthcare domain under "Command and Control" category, Apparel domain under Supply/Demand category, Mortgage under "Financial" category and Lease and Finance under "Business Application" category.

TABLE 1. COMPANY WISE MATURITY RANKING DISTRIBUTION OF PROJECTS

\begin{tabular}{|c|c|}
\hline Companies & Maturity Level (Number of Projects) \\
\hline Company-A & $0(15 / 18), 1(10 / 14), 2(6 / 7)$ \\
\hline Company-B & $3(2 / 2), 4(4 / 4), 5(17 / 17)$ \\
\hline Company-C & $3(4 / 5)$ \\
\hline
\end{tabular}

In Questionnaire, both quantitative and qualitative fields were given along with the complete definition of each field for user understanding. It consists of two main sections in which section A covers all quantitative metrics such as:

(1) Project Schedule Actual and Estimated

(2) Project Size Actual.

(3) Project Cost Actual and Estimated.

(4) Project Effort Actual and Estimated.

(5) Productivity as a ratio of software size with development effort.

Whereas, the section B of Questionnaire covers COCOMO-II questionnaire, which is a pre-tested wellknown questionnaire and needs no pilot testing [31]. For a detailed definition, and structure details of variables shown in Table 2.

The questionnaire validity was evaluated by the field experts and pre-tested by the senior Quality Manager from its intended domain. It has been checked for confirming that the measuring instrument is measuring what it intends to measure i.e. there should be no multiple interpretations in metric headings and definitions and also there should be no inappropriate and unclear wordings by authors.

Then its reliability was checked, as the reliability of measurement instrument is required to be checked in cases where a scale items are used and their final value is calculated from a total score of set of items from which the scales have been composed. Although we have not used such scales, still we applied it on those sets of metrics which were representing a common construct or metric. For example Schedule_Actual, and Schedule_Planned are representing Schedule construct. The Cronbach's Alpha test was performed to check the reliability of all ESCP constructs. The results in Table 3 indicate that those variables who were making pairs meet the reliability requirement as Cronbach's alphas ranged from 0.6-1 which is under the range of defined reliability level [32]. 
TABLE 2. METRIC DEFINITIONS

\begin{tabular}{|c|c|c|c|}
\hline Metric & Definition & Reference & Measurement Type \\
\hline \multicolumn{4}{|c|}{ Section-A: Project Effort } \\
\hline PM or Effort_Actual (A) & $\begin{array}{l}\text { It represents Total Actual Effort in Hours. Project effort is the total team time that is spent on project related } \\
\text { activities during project life cycle. It is the sum of "Working Hours" of the following persons who have worked } \\
\text { on their assigned Software Engineering activities at Job: } 1 \text {. Requirements Analyst } 2 \text {. Software Developer's time } \\
\text { (planning, design, code, test, rework, integration), 3. Project Management time } 4 \text {. Project Support is the team } \\
\text { time consumed in configuration management and quality assurance. 5. Training. } \\
\text { Internationally it is taken as } 152 \text { hours/Person Month (PM). }\end{array}$ & {$[13,5]$} & $\begin{array}{l}\text { Objective/ } \\
\text { Quantitative }\end{array}$ \\
\hline PM or Effort_Estimated (E) & It represents planned value of Total Effort in Hours. Value of Effort you Planned for your project & [13] & $\begin{array}{l}\text { Objective/ } \\
\text { Quantitative }\end{array}$ \\
\hline \multicolumn{4}{|c|}{ Project Schedule \& Duration } \\
\hline $\begin{array}{l}\text { TDEV or Schedule_Actual } \\
\text { (A) }\end{array}$ & $\begin{array}{l}\text { It shows actual project duration in hours. It is a measure of project length in "Work Hours" excluding the time of } \\
\text { work stoppages. Project start is the date when user requirements are baselined and project end date is the date } \\
\text { of the first software installation at client side. }\end{array}$ & [13] & $\begin{array}{l}\text { Objective/ } \\
\text { Quantitative }\end{array}$ \\
\hline $\begin{array}{c}\text { TDEV or Schedule_Estimated } \\
\text { (E) }\end{array}$ & $\begin{array}{l}\text { It shows planned project duration in hours. Project's Estimated or Planned value for duration made once the } \\
\text { requirements get signed off. }\end{array}$ & [13] & $\begin{array}{l}\text { Objective/ } \\
\text { Quantitative }\end{array}$ \\
\hline Working Hours in Month & Number of working hours in one month. & [13] & $\begin{array}{l}\text { Objective/ } \\
\text { Quantitative }\end{array}$ \\
\hline \multicolumn{4}{|c|}{ Project Size } \\
\hline EquivalentSizeLOC & $\begin{array}{l}\text { It is a measure of product's equivalent size in LOC (Lines of Code), following COCOMO-II standard model } \\
\text { definition. }\end{array}$ & [13] & $\begin{array}{l}\text { Objective/ } \\
\text { Quantitative }\end{array}$ \\
\hline \multicolumn{4}{|c|}{ Project Cost } \\
\hline $\begin{array}{l}\text { Cost or ProductUnitPricein } \\
\text { Dollar_Actual (A) }\end{array}$ & $\begin{array}{l}\text { It shows an actual unit price of a product in a market. Companies were unable to quote original selling prices of } \\
\text { their developed products as it has no standard. We have calculated it as = Effort_Actual * } \\
\text { AvgSalaryDrawnByTechPersonnel Per Hour. It is same as product cost used for calculating other metrics, } \\
\text { following COCOMO-II standard model defination. }\end{array}$ & [13] & $\begin{array}{l}\text { Objective/ } \\
\text { Quantitative }\end{array}$ \\
\hline $\begin{array}{l}\text { Cost or } \\
\text { ProductUnitPriceInDollar_Pla- } \\
\text { nned (P) }\end{array}$ & $\begin{array}{l}\text { It shows planned unit price of a product in a market. Companies were unable to quote original selling prices of } \\
\text { their developed products as it has no standard. We have calculated it as = Effort_Planned * } \\
\text { AvgSalaryDrawnByTechPersonnel Per Hour. It is same as product cost used for calculating other metrics, } \\
\text { following cocomo II standard model definition. }\end{array}$ & [13] & $\begin{array}{l}\text { Objective/ } \\
\text { Quantitative }\end{array}$ \\
\hline $\begin{array}{l}\text { Avg Salary Drawn By Tech } \\
\text { Personnel Per Hour }\end{array}$ & It represents an average salary in dollars, drawn by a technical personnel. & [13] & $\begin{array}{l}\text { Objective/ } \\
\text { Quantitative }\end{array}$ \\
\hline \multicolumn{4}{|c|}{ Productivity } \\
\hline Productivity & It shows work productivity and is measured as a ratio of Output produced in terms of LOC with Effort. & [13] & $\begin{array}{l}\text { Objective/ } \\
\text { Quantitative }\end{array}$ \\
\hline \multicolumn{4}{|c|}{ Section-B: SDPI } \\
\hline $\begin{array}{l}\text { PMAT or Process Maturity } \\
\text { Ranking }\end{array}$ & $\begin{array}{l}\text { It is also known as PMAT or SDPI and represents organization's maturity level. We have made sure that the } \\
\text { Organization's ISO certification status or CMMI ranking should have gone through Class-A appraisal before the } \\
\text { projects were started for development and it should have been completed within the validity of apprised } \\
\text { certification or framework, see SW-CMMI levels or Organization's Maturity Level Scaling Factor bellow. }\end{array}$ & & $\begin{array}{l}\text { Subjective/ } \\
\text { Qualitative }\end{array}$ \\
\hline $\begin{array}{l}\text { COCOMO-II Questionnaire } \\
\text { Cost Drivers }\end{array}$ & $\begin{array}{l}5 \text { Project Exponential Cost Drivers or Scaling Factors and } 17 \text { Post-Architecture Effort Multipliers are grouped } \\
\text { into four categories like platform, product, personnel, and project. For details check reference. }\end{array}$ & [31] & $\begin{array}{l}\text { Subjective/ } \\
\text { Qualitative }\end{array}$ \\
\hline Scaling Factors & $\begin{array}{l}\text { Five scaling factors are given as under, among which three parameters Risk Resolution, Team Cohesion, and } \\
\text { PMAT are management controllable Knobs, adjusting which we could reduce sources of project turbulence (fuss), } \\
\text { entropy, and rework. } \\
\text { - Precedentedness: Product is similar to previously developed projects } \\
\text { - Flexibility for development: The level of conformity of requirements } \\
\text { - Risk Resolution: Design thoroughness by product design review PDR and Risk elimination } \\
\text { by PDR } \\
\text { - Team Cohesion: level of lack of coordination in team members, difficulties in synchronizing } \\
\text { the project's stakeholder. } \\
\text { - SW-CMMI levels or Organization's Maturity Level: Represents the organization's CMM ranking at the time } \\
\text { when the project was ready to develop. It represents the Satisfaction rating for each process area for the claimed } \\
\text { Maturity level, to make sure that all related Process Areas have shown the satisfactory level at the time of class } \\
\text { A appraisal. }\end{array}$ & & \\
\hline Effort Multipliers & $\begin{array}{l}\text { Seventeen effort multipliers are related to product, personal, and project includes following parameters: } \\
\text { Product Attributes } \\
\text { - Software Reliability } \\
\text { - Size of Database } \\
\text { - Complexity of Product } \\
\text { - Execution Time Constraint } \\
\text { - Main Storage Constraint } \\
\text { - Virtual Machine Volatility } \\
\text { - Computer Turn Around Time } \\
\text { Personal Attributes } \\
\text { - Capability of Analyst } \\
\text { - Application Experience } \\
\text { - Capability of Programmer } \\
\text { - Virtual Machine Experience } \\
\text { - Programming Language Experience } \\
\text { Project Attributes } \\
\text { - Use of Modern Programming Practices } \\
\text { - Use of Software Tool } \\
\text { - Required Development Schedule }\end{array}$ & [31] & $\begin{array}{l}\text { Subjective/ } \\
\text { Qualitative }\end{array}$ \\
\hline
\end{tabular}

Mehran University Research Journal of Engineering \& Technology, Volume 35, No. 4, October, 2016 [p-ISSN: 0254-7821, e-ISSN: 2413-7219] 


\subsubsection{COCOMO-II Cost Drivers}

Prediction variables usually used in estimation models represent the benefit measurement classes ESCP through which SDPI benefits are measured. Furthermore, 22 cost drivers have been recorded, which consists of five scaling factors and 17 effort multipliers. These qualitative cost drivers have a direct impact on software development projects therefore, it was necessary to record them for generating process improvement benefit predictions.

\subsubsection{Interpretation of SDPI Levels or PMAT Scale Factor}

Different increasing levels of software development process maturity are represented by a qualitative variable of PMAT Process Maturity Rating or SDPI levels. Table 4 indicates the adopted interpretations of different SDPI measurement levels.

\subsection{Demographics}

The demographic data i.e. size, structure, and distribution of these populations concluded that the number of available experienced respondents were belonged to the engineering and management disciplines (Table 5), which shows they have good understanding of development practices and were capable enough to provide a qualified assessment. The respondents consisted of Quality Managers having approximately 10 years of field experience in process improvement field, which strengthens the collected data's reliability.

TABLE 3. RELIABILITY TEST

\begin{tabular}{|c|c|}
\hline Benefit Measurement Classes & Cronbach Alpha \\
\hline $\begin{array}{c}\text { Effort: EffortinHour_Actual, } \\
\text { EffortinHour_Estimated }\end{array}$ & 0.62 \\
\hline $\begin{array}{c}\text { Schedule: Schedule_Actual, } \\
\text { Schedule_Estimated }\end{array}$ & 0.73 \\
\hline $\begin{array}{c}\text { Cost: Product Unit Pricein } \\
\text { Dollar_Actual, Product Unit Price } \\
\text { In Dollar_Estimated }\end{array}$ & 0.62 \\
\hline Productivity (n/a) & Not applicable \\
\hline
\end{tabular}

\subsection{Evaluation of Prediction Accuracy}

As discussed in research studies [21,19], the major highlighted prediction accuracy measures used in this research include the following measures:

TABLE 4. SDPI SCORES AND DEFINITIONS

\begin{tabular}{|c|c|}
\hline $\begin{array}{c}\text { SDPI } \\
\text { Level/PMAT }\end{array}$ & $\begin{array}{c}\text { SDPI Framework, CMMI ML maturity levels and } \\
\text { measurement practices }\end{array}$ \\
\hline 0 & No SDPI framework or practices followed. \\
\hline 1 & $\begin{array}{c}\text { CMMI Maturity Level 1: The organization has failed } \\
\text { to attain CMMI level 2. }\end{array}$ \\
\hline 2 & $\begin{array}{c}\text { CMMI Maturity Level 2: It requires measures for } \\
\text { project statuses like prediction accuracy for size, } \\
\text { effort, cost, and schedule; the number of changes } \\
\text { and non-conformances in process and product. }\end{array}$ \\
\hline 3 & $\begin{array}{c}\text { CMMI Maturity Level 3: It requires measurement } \\
\text { for process improvement and quality including the } \\
\text { defect density and productivity. }\end{array}$ \\
\hline 4 & $\begin{array}{c}\text { CMMI Maturity Level 4: It requires the creation } \\
\text { and usage of PPBs (Process Performance Baseline) } \\
\text { and PPMs (Process Performance Models). PPBs } \\
\text { and PPMs are based on historical data from lower } \\
\text { levels. }\end{array}$ \\
\hline 5 & $\begin{array}{r}\text { CMMI Maturity Level 5: It involves the } \\
\text { demonstration of quantitative improvements based } \\
\text { on baselines [29,33]. }\end{array}$ \\
\hline
\end{tabular}

TABLE 5. DEMOGRAPHIC INFORMATION

\begin{tabular}{|c|c|}
\hline Gender & Quantity (Number) \\
\hline Males & 3 \\
\hline Females & 1 \\
\hline \multicolumn{2}{|c|}{ Industry } \\
\hline Software Development & 3 \\
\hline \multicolumn{2}{|l|}{ Position } \\
\hline Quality Manager & 3 \\
\hline \multicolumn{2}{|c|}{ Year of Experience } \\
\hline Equals to and greater than 10 years & N/A \\
\hline \multicolumn{2}{|c|}{ Field of Experience } \\
\hline Software Process Improvement & N/A \\
\hline
\end{tabular}

Mehran University Research Journal of Engineering \& Technology, Volume 35, No. 4, October, 2016 [p-ISSN: 0254-7821, e-ISSN: 2413-7219] 
- $\quad \operatorname{MMRE}$ (Mean Magnitude of Relative Error) is an average of the sum of the absolute MRE over multiple observations $\mathrm{N}$. It is calculated as $\left(\mathrm{O}_{\mathrm{i}=1-\mathrm{N}}\right.$ $\left.M R E_{\mathrm{i}}\right) / \mathrm{N}$.

- $\quad$ PRED measure shows that the K number of MREi prediction readings are within $\mathrm{L} \%$ level variance and is given as $\operatorname{PRED}(\mathrm{L} \%)=(\mathrm{K} / \mathrm{N}) * 100$.

- It involves breaking of data sets into organization wise separate groups so such that the overall prediction accuracy improves within a group as compared to the mix data set.

\section{RESULTS AND DATAANALYSIS}

Excel spreadsheet was used for performing the major calculations and data analysis in this research:

Against each data set ESCP has been calculated using equations given in Section 4.1 (Table 2 for definitions).

(b) Verification of ISF formula is made which has been used in a book [25] and a research paper [26] for calculating parameters given in power section of COCOMO Equation (1). (c) A formula has been derived from main COCOMO model Equation (1) for calculating the ideal value for scale factors ISF.

(d) A selected model is tuned to bring prediction capability for SDPI benefit measurement classes such as Effort, Schedule, Cost, and Productivity using the Ideal Scale Factor analysis (Section 2.2 for its background details).

(e) Model prediction accuracy has been checked using the MMRE and PRED measure by comparing the ESCP values calculated from old value of PMAT with the ESCP values calculated from PMAT value calculated in this research (Section 3.4 for its background detail).

\subsection{Basic Calculations}

While performing the defined data analysis, the following calculations have been made in sequence. In Tables 6-7 it shows that data has been collected against COCOMO Scaling Factors and Effort Multipliers.

In Tables 8-16 against the collected values of KLOC (Kilo Line of Code) for 62 projects the estimated value of ESCP has been calculated using metric formulas given as under:

TABLE 6. SCALING FACTORS AND EFFORT MULTIPLIERS

\begin{tabular}{|c|c|c|c|c|c|c|c|c|c|}
\hline $\begin{array}{c}\text { Project's } \\
\text { Resemblance } \\
\text { to previously } \\
\text { developed } \\
\text { Project- } \\
\text { PREC }\end{array}$ & $\begin{array}{c}\text { Degree of } \\
\text { Conformance } \\
\text { Enforced to } \\
\text { Requirements } \\
\text { and Schedule- } \\
\text { FLEX }\end{array}$ & $\begin{array}{l}\text { Architecture } \\
\text { and Risk } \\
\text { Resolution- } \\
\text { RESL }\end{array}$ & $\begin{array}{l}\text { Stakeholder } \\
\text { Sticking } \\
\text { Together } \\
\text { Cohesion- } \\
\text { TEAM }\end{array}$ & $\begin{array}{l}\text { Organizational } \\
\text { Process } \\
\text { Maturity } \\
\text { Ranking- } \\
\text { PMAT }\end{array}$ & $\begin{array}{l}\text { Required } \\
\text { Software } \\
\text { Reliability- } \\
\text { RELY }\end{array}$ & $\begin{array}{c}\text { Product Data } \\
\text { Size- } \\
\text { DATA }\end{array}$ & $\begin{array}{l}\text { Product } \\
\text { develop for } \\
\text { reuse- } \\
\text { REUSE }\end{array}$ & \begin{tabular}{|c|} 
Product \\
Documentation \\
match to \\
lifecycle \\
needs- \\
DOCU
\end{tabular} & $\begin{array}{c}\text { Product } \\
\text { Complexity- } \\
\text { CPLX }\end{array}$ \\
\hline VL: 6.2 & H: 2.03 & VL: 7.07 & VH: 1.1 & EL: 7.8 & L: 0.92 & L: 0.9 & VH: 1.15 & VL: 0.81 & $\mathrm{~L}: 0.87$ \\
\hline
\end{tabular}

TABLE 7. EFFORT MULTIPLIERS

\begin{tabular}{|c|c|c|c|c|c|c|c|c|c|c|c|}
\hline $\begin{array}{l}\text { Platform } \\
\text { Execution } \\
\text { Time } \\
\text { Constraint- } \\
\text { Time }\end{array}$ & $\begin{array}{l}\text { Platform } \\
\text { Main } \\
\text { Storage } \\
\text { Constraint- } \\
\text { STOR }\end{array}$ & $\begin{array}{l}\text { Platform } \\
\text { Volatility- } \\
\text { PVOL }\end{array}$ & $\begin{array}{l}\text { Personnel } \\
\text { Analyst } \\
\text { Capability- } \\
\text { ACAP }\end{array}$ & $\begin{array}{c}\text { Personnel } \\
\text { Programmer } \\
\text { Capability- } \\
\text { PCAP }\end{array}$ & $\begin{array}{l}\text { Personal, } \\
\text { Project's } \\
\text { Annual } \\
\text { personnel } \\
\text { Turnover or } \\
\text { Continuity- } \\
\text { PCON } \\
\end{array}$ & $\begin{array}{l}\text { Personal, } \\
\text { Team } \\
\text { experience } \\
\text { with } \\
\text { Application } \\
\text { APEX }\end{array}$ & $\begin{array}{l}\text { Personal, } \\
\text { Team } \\
\text { experience- } \\
\text { PLEX }\end{array}$ & $\begin{array}{l}\text { Personal, } \\
\text { Team's } \\
\text { language \& } \\
\text { Tool } \\
\text { Experience- } \\
\text { LTEX }\end{array}$ & $\begin{array}{c}\text { Project, } \\
\text { Use } \\
\text { of Software } \\
\text { Tool- } \\
\text { TOOL }\end{array}$ & $\begin{array}{c}\text { Project } \\
\text { Multisite } \\
\text { Dev. } \\
\text { (Location \& } \\
\text { Comm.)- } \\
\text { SITE }\end{array}$ & $\begin{array}{l}\text { Schedule } \\
\text { Expansion } \\
\text { required- } \\
\text { SCED }\end{array}$ \\
\hline $\mathrm{N}: 1$ & $\mathrm{~N}: 1$ & $\mathrm{~L}: 0.87$ & $\mathrm{~N}: 1$ & $\mathrm{~N}: 1$ & $\mathrm{~L}: 1.12$ & H: 0.88 & $\mathrm{H}: 0.91$ & $\mathrm{H}: 0.91$ & $\mathrm{~N}: 1$ & $\mathrm{~N}: 1$ & $\mathrm{H}: 1$ \\
\hline
\end{tabular}

Mehran University Research Journal of Engineering \& Technology, Volume 35, No. 4, October, 2016 [p-ISSN: 0254-7821, e-ISSN: 2413-7219] 


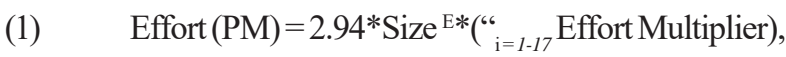
where $E=\left(0.91+0.01 *{ }_{j=1-5}\right.$ Scaling Factor $)$ and Size is measured in KLOC.

Schedule $(\mathrm{TDEV})=3.67 * \mathrm{PM}^{\mathrm{F}} * \mathrm{SCHED}$, where $\mathrm{F}=0.28+0.2 * 0.01 *{ }_{j=1-5}$ Scaling Factor, and SCHED represents percent stretch in nominal schedule.

Software Development Cost $=$ Effort $(\mathrm{PM}) *$ Average Salary per Month.

Productivity $=$ Project Size in Line of Code/Effort.

\subsection{ISF Analysis}

IEM is defined as, "for a project $\mathrm{P}$, calculate estimated effort using COCOMO model with an exception of not to include the EM for the cost driver attribute which is under observation. Then the IEM for the selected project and cost driver attribute combination is the one which, if used in COCOMO, would make the estimated PM for the project equals to its actual effort PM". To apply the IEM or ISF analysis method as given in research [26] and discussed in Section 2.2, its formula has been verified which is given as under:

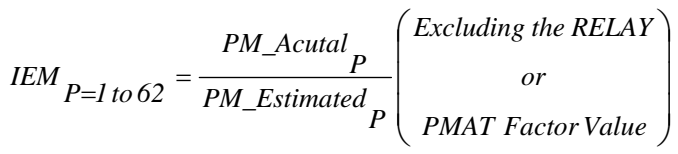

Following the verification rule given in reference [25] i.e. "If an Estimation model is perfect, the IEM for each project (P) would be equal to the corresponding COCOMO effort

TABLE 8. EFFORT ESTIMATION USING COCOMO PA MODEL

\begin{tabular}{|c|c|}
\hline KLOC & Effort Estimated using COCOMO \\
\hline 126.71 & 403.88 \\
\hline 59.89 & 170.34 \\
\hline 41.93 & 105.11 \\
\hline
\end{tabular}

multiplier", there is a need of driving IEM formula using which, if we take COCOMO generated estimates as an actual effort value then the generated IEM value should be exactly the same corresponding COCOMO effort multiplier value. While doing so, we have first rearranged the equation 1 to derive any Effort Multiplier factor. This rearrangement results in exactly the same formula given as Equation (2).

Before going any further, we have verified it by taken available project's COCOMO-II Post Architecture model's estimated effort value as an actual effort and divided it with its estimated value which has been calculated while excluding the value of RELY Effort Multiplier for its "Very Low" project readings. The generated outcome was 0.82 which is the same value of COCOMO Effort Multiplier.

Then Equation (2) has been verified for calculating the ideal values for Scaling Factors. For this verification, the project's COCOMO-II PostArchitecture model's estimated effort value was taken as an actual effort and divided with its estimated value which has been calculated while excluding the value of PMAT Scaling Factor for its Very Low project readings. For CMMI level 0 projects above formula should give its output exactly the same as PMAT scaling factor's beta coefficient value i.e. 7.80, instead it was giving a value of 1.27. Table 9 has shown this verification and the originally calculated value using the above Equation (2). On getting unverifiable results, we have solved the Equation 1 to derive the scaling factor value, that could be used to give verifiable results, see Equation (3) given as under.

$I S F-S F_{P=1 \text { to } 62}=\left[\left(\begin{array}{c}\text { Log of PM }- \text { Log of } \\ \frac{A-\log \text { of } E A F-\left(B^{*} \log \text { of Size }\right)}{0.01^{*} \log \text { of Size }}\end{array}\right)\right]-$ SFbuPmat

TABLE 9. VERIFICATION OF ISF FORMULA USED BY MALAYSIAN RESEARCHERS

\begin{tabular}{|c|c|c|}
\hline $\begin{array}{c}\text { PM Estimated using } \\
\text { COCOMO }\end{array}$ & $\begin{array}{c}\text { PM Estimated } \\
\text { COCOMO but PMAT }\end{array}$ & $\begin{array}{c}\text { Verification of ISF by } \\
\text { Malaysian Researchers }\end{array}$ \\
\hline 403.88 & 276.84 & 1.46 \\
\hline 170.34 & 123.79 & 1.38 \\
\hline 105.11 & 78.54 & 1.34 \\
\hline & Mean & 1.27 \\
\hline
\end{tabular}

Mehran University Research Journal of Engineering \& Technology, Volume 35, No. 4, October, 2016 [p-ISSN: 0254-7821, e-ISSN: 2413-7219] 
Where ISF-SF is ISF for Scaling Factor, here ISF-SF is ISFPMAT, PM is Effort in Person Months, A is Constant of 2.94, B is Constant of 1.01, Size is Project size measured in KLOC Kilo Line of Code, SFbutPmat is “ ${ }_{\mathrm{j}=1-5}$ Scaling Factor, and EAF is “ ${ }_{\mathrm{i}=1-17}$ Effort Multiplier.

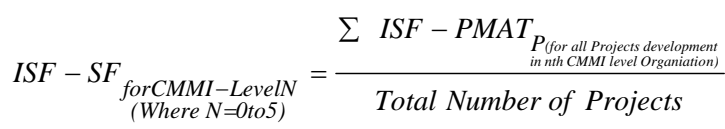

After calculating ISF-PMAT for each individual project, the mean value has been calculated for each group of varying CMMI Levels using Equation (4) to derive final ISF values representing their particular groups. Table 10 shows the correct verification of ISF value which has been calculated on previously defined parameters (Equation (2)). After formula verification, it was ready for calculating ISF value for this research's dataset. Table 11 gives ISF values calculated from different Methods.

Fig. 4 shows ISF-PMAT values of all models, where a line with triangle data points shows ISF-PMAT of this research, and the one with square data points shows PMAT-CMM value of COCOMO-II Post Architecture model. COCOMOII Post Architecture model's PMAT value shows that when Process Maturity level increases the Effort value decreases.

The ISF-PMAT of this research has shown a somewhat inverse trend of ISF change, which means that an increase in ISF value with an increase in Process Maturity level till ML3 and a smooth decrease in Effort from ML-3 toward ML-5 reflects an increase in Effort value.

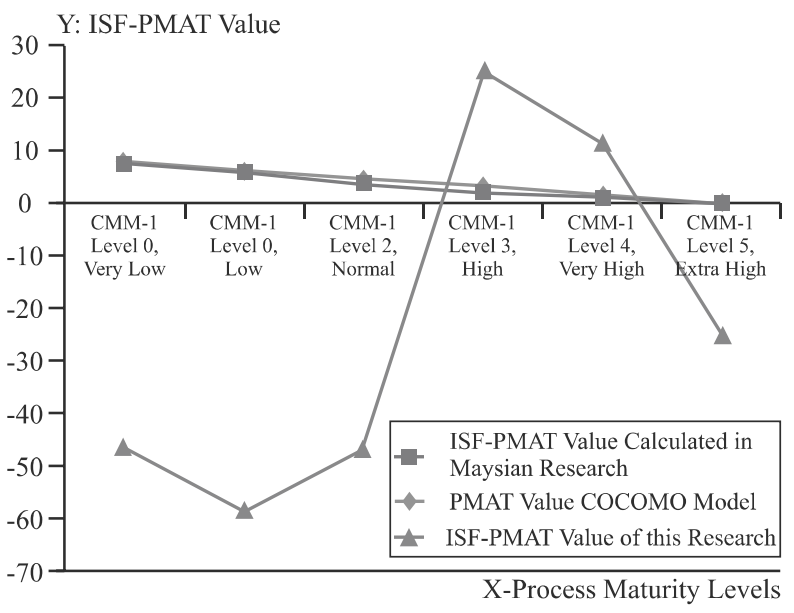

FIG. 4. ISF-PMAT VALUES OF ALL MODELS (X AND Y AXIS)

TABLE 10. VERIFICATION OF NEW DERIVED ISF FORMULA AND CALCULATION OF ISF VALUE FOR THIS RESEARCH

\begin{tabular}{|c|c|c|c|c|c|c|c|c|c|c|}
\hline $\begin{array}{l}\text { PM Actual } \\
\text { Reported }\end{array}$ & $\log (\mathrm{PM})$ & $\begin{array}{c}\log (\mathrm{PM} \\
\text { COCOMO) }\end{array}$ & $\log (A)$ & EM & $\log (\mathrm{EM})$ & Log (Size) & $\begin{array}{l}\text { SF but } \\
\text { PMAT }\end{array}$ & B & $\begin{array}{c}\text { ISF Formula } \\
\text { Verification } \\
\text { PM_COCOMO } \\
\text { Estimated }\end{array}$ & $\begin{array}{l}\text { ISF of this } \\
\text { research } \\
\text { PM_Actual } \\
\text { Reported }\end{array}$ \\
\hline 52.79 & 1.72 & 2.61 & 0.47 & 0.52 & -0.28 & 2.10 & 16.40 & 0.91 & 7.80 & -34.23 \\
\hline 48.24 & 1.68 & 2.23 & 0.47 & 0.52 & -0.28 & 1.78 & 16.40 & 0.91 & 7.80 & -23.03 \\
\hline 19.23 & 1.28 & 2.01 & 0.47 & 0.74 & -0.13 & 1.64 & 15.16 & 0.91 & 7.80 & -48.55 \\
\hline & & & & & & & & Mean & 7.80 & -46.50 \\
\hline
\end{tabular}

TABLE 11. PMAT VALUES IN ALL MODELS

\begin{tabular}{|c|c|c|c|c|c|c|}
\hline Model & $\begin{array}{c}\text { CMM-I Level-0, } \\
\text { Very Low }\end{array}$ & $\begin{array}{c}\text { CM-I Level01, } \\
\text { Low }\end{array}$ & $\begin{array}{c}\text { CMM-I Level-2, } \\
\text { Nominal }\end{array}$ & $\begin{array}{c}\text { CMM-I Level-3, } \\
\text { High }\end{array}$ & $\begin{array}{c}\text { CMM-I Level-4, } \\
\text { Very High }\end{array}$ & $\begin{array}{c}\text { CMM-I Level-5, } \\
\text { Extra High }\end{array}$ \\
\hline COCOMO PA, PMAT-CMM & 7.8 & 6.24 & 4.68 & 3.12 & 1.56 & 0 \\
\hline Malaysian ISF-PMAT & 1.25 & 5.67 & 3.7 & 2.04 & 0.96 & 0 \\
\hline IEM-PMAT values & 1.27 & 1.17 & 1.14 & 1.07 & 1.05 & 1 \\
\hline This Research's ISF-PMAT & -46.5 & -58.66 & -46.82 & -1.88 & 11.36 & -25.32 \\
\hline
\end{tabular}

Mehran University Research Journal of Engineering \& Technology, Volume 35, No. 4, October, 2016 [p-ISSN: 0254-7821, e-ISSN: 2413-7219] 


\subsection{Model Prediction Accuracy}

Among the model prediction accuracy checking methods discussed in research [19] MMRE, and PRED (30) criterions have been used to assess the prediction accuracy of COCOMO's prediction with the new model's prediction. Tables 12-16 have shown the sample calculations that have been performed for calculating MRE, MMRE, and PRED (30) values for COCOMO model, Malaysian model, and this research's New model comparisons. Table 17 has shown the improvement in results from this research's model with old COCOMO model's prediction accuracy.

Table 17 has shown that our results are in contrast to the results of COCOMO PA model. This study brings improvement in PRED (30) value of Effort (PM) for COCOMO PA model for organizations at CMMI level 0 by $57 \%$, at CMMI Level 1 by $40 \%$, at CMMI Level 2 by 100\%, at CMMI Level 3 by $0 \%$, at CMMI Level 4 by $0 \%$, and at CMMI Level 5 by $17 \%$ respectively. It also shows improvement in PRED (30) value of Schedule (TDEV) for COCOMO PA model for organizations at CMMI level 0 by $-57 \%$, at CMMI Level 1 by $0 \%$, at CMMI Level 2 by $20 \%$, at CMMI Level 3 by 25 $50 \%$, at CMMI Level 4 by $0 \%$, and at CMMI Level 5 by $0 \%$ respectively. The reason of negative improvement value for estimated TDEV on ML-0 is the reporting of same constant time period used for all type of projects. Whereas, the

TABLE 12. COCOMO MODEL PREDICTION ACCURACY

\begin{tabular}{|c|c|c|c|}
\hline KLOC & $\begin{array}{c}\text { PM Estimated } \\
\text { COCOMO }\end{array}$ & $\begin{array}{c}\text { PM Actual } \\
\text { Reported }\end{array}$ & MRE \\
\hline 126.7 & 403.88 & 52.79 & 6.65 \\
\hline 59.89 & 170.34 & 48.24 & 2.53 \\
\hline \multicolumn{3}{|c|}{ Mean } & 4.35 \\
\hline \multicolumn{3}{|c|}{$\operatorname{PRED(30)~}$} & 0 \\
\hline
\end{tabular}

improvement brought in PRED (30) value of Project Cost (COST) for COCOMO PA model for organizations at CMMI level 0 by $64.29 \%$, at CMMI Level 1 by $40 \%$, at CMMI Level 2 by $100 \%$, at CMMI Level 3 by $0 \%$, at CMMI Level 4 by $66.67 \%$, and at CMMI Level 5 by $0 \%$ respectively. And the improvement brought in PRED (30) value of Project Productivity (PROD) for COCOMO PA model for organizations at CMMI level 0 by $85.71 \%$, at CMMI Level 1 by $20 \%$, at CMMI Level 2 by $80 \%$, at CMMI Level 3 by $0 \%$, at CMMI Level 4 by $0 \%$, and at CMMI Level 5 by $0 \%$ respectively. Graphical Representation and Research Questions

Fig. 5 represents the inter-model comparisons graphically.

In Fig. 5 the horizontal $\mathrm{x}$-axis represents 5 projects of CMMI level organizations, and the vertical $y$-axis represents the Person Month measure as well as the KLOC value scale. We have five bars against each project data, among which starting from the left side the $1^{\text {st }}$ bar represents KLOC size of project, $2^{\text {nd }}$ bar represents $P M$ actual reported, $3^{\text {rd }}$ bar represents PM estimated from COCOMO PA model, $4^{\text {th }}$ bar represents PM estimated from ISF-PMAT values derived in Malaysian study [26], and the $5^{\text {th }}$ bar is PM estimated from ISF-PMAT value which is calculated in this research. All above graphs witnesses that the estimated effort calculated from the ISF-PMAT value of this research gives closer value

TABLE 14. CURRENT RESEARCH MODEL PREDICTION ACCURACY

\begin{tabular}{|c|c|c|}
\hline $\begin{array}{c}\text { PM Estimated from } \\
\text { PMAT of this Research }\end{array}$ & PM Actual Reported & MRE \\
\hline 29.14 & 52.79 & 0.45 \\
\hline 18.46 & 48.24 & 0.62 \\
\hline \multicolumn{2}{|c|}{ Mean } & 0.28 \\
\hline \multicolumn{2}{|c|}{ PRED(30) } & 57.14 \\
\hline
\end{tabular}

TABLE 13. MALAYSIAN MODEL PREDICTION ACCURACY

\begin{tabular}{|c|c|c|c|c|c|}
\hline $\begin{array}{c}\text { PM Estimated } \\
\text { using COCOMO }\end{array}$ & $\begin{array}{c}\text { PM Estimated } \\
\text { COCOMO but } \\
\text { Excluding PMAT }\end{array}$ & $\begin{array}{c}\text { Verification of ISF } \\
\text { Calculated by } \\
\text { Malaysian Researchers }\end{array}$ & $\begin{array}{c}\text { PM Estimated from } \\
\text { PMAT of } \\
\text { Malaysians }\end{array}$ & $\begin{array}{c}\text { PM Actual } \\
\text { Reported }\end{array}$ & MRE \\
\hline 403.88 & 276.84 & 1.46 & 393.27 & 52.79 & 6.45 \\
\hline 170.34 & 123.79 & 1.38 & 166.55 & 48.24 & 2.45 \\
\hline \multicolumn{2}{|c|}{ Mean } & 1.27 & & & 4.26 \\
\hline
\end{tabular}

Mehran University Research Journal of Engineering \& Technology, Volume 35, No. 4, October, 2016 [p-ISSN: 0254-7821, e-ISSN: 2413-7219] 
to the Actual effort value reported in the collected data set of this research. All tabular and graphical data in Section 4 summarizes acceptance of research question that was raised in earlier Section. Table 18 shows a better prediction accuracy of this research's model than the original COCOMO model. It answers the Research Question RQ 1and shows that the prediction of this research's model reflects more accurate Predictions for ESCP values than the original COCOMO model, which makes it suitable for usage in Pakistani software industry

If we focus over Effort value, which is the major factor of calculating other factor schedule, cost, and productivity, Table 19 helps in answering the RQ2 and shows that the prediction accuracy of COCOMO model tuned using IEM method is not better than the prediction accuracy of COCOMO model tuned using ISF method of this research.

\section{THREATS TO RESEARCH VALIDITY}

In this section we have discussed the major threats to the validity of this study as recommended in research notes by [34]. First of all the majority of organizations in the software industry have not maintained very detailed historical data repository, therefore, some metrics for which we have collected data are in percent form of some quantitatively selected data. An expert opinion has been used for data collection from senior QA (Quality Assurance) personnel which were involved at the time when software were developed. It has been observed in the targeted companies that once they go through whole process of SPI their software development and process related metric data is maintained and managed by the SQA (Software Quality Assurance) department although they have Quality Managers. However, their SQA managers are more responsible for data related issues. It could be mentioned that on the recommendation of QA Managers SQA Managers have been contacted for reporting project level details.

Furthermore, data collected in the questionnaire was not verified from their original resources as it was collected from the historical data repository. The data is collected from 3 most efficient organizations of Pakistan, which can limit the a generalization of this research, but these companies are representative of the software industry in Pakistan who has successfully achieved higher SDPI levels. Although, the number of companies taking part in the case studies are low in number, perhaps the number is sufficient to draw general conclusions.

TABLE 15. BASIC CALCULATIONS FOR TDEV, PROJECT COST, AND MMRE VALUE

\begin{tabular}{|c|c|c|c|c|c|c|c|c|c|}
\hline $\begin{array}{c}\text { TDEV Actual } \\
\text { Reported }\end{array}$ & $\begin{array}{c}\text { TDEV } \\
\text { Estimated } \\
\text { COCOMO }\end{array}$ & MRE & $\begin{array}{c}\text { TDEV Estimated } \\
\text { from ISF-PMAT of } \\
\text { this Research }\end{array}$ & MRE & $\begin{array}{c}\text { Cost } \\
\text { Actual }\end{array}$ & $\begin{array}{c}\text { Cost Estimated } \\
\text { COCOMO }\end{array}$ & MRE & $\begin{array}{c}\text { Cost Estimated } \\
\text { from ISF-PMAT of } \\
\text { this Research }\end{array}$ & $\begin{array}{c}\text { MRE } \\
12\end{array}$ \\
\hline 12 & 15.46 & 0.95 & 4.61 & 0.62 & 3570 & 7158.39 & 1.01 & 3491.24 & 0.02 \\
\hline 12 & 0.98 & 6.55 & 0.45 & 19510 & 103406.50 & 4.30 & 17129.44 & 0.12 \\
\hline \multicolumn{2}{|c|}{ Mean } & 0.97 & Mean & 0.49 & & Mean & 3.58 & Mean & 0.15 \\
\hline \multicolumn{2}{|c|}{ PRED(30) } & 0 & PRED(30) & 20 & & PRED(30) & 0 & PRED(30) & 100 \\
\hline
\end{tabular}

TABLE 16. BASIC CALCULATIONS FOR PROJECT PRODUCTIVITY, AND MMRE VALUE

\begin{tabular}{|c|c|c|c|c|}
\hline Productivity Actual Reported & $\begin{array}{c}\text { Productivity Estimated } \\
\text { COCOMO }\end{array}$ & MRE & $\begin{array}{c}\text { Productivity Estimated from } \\
\text { ISF-PMAT of this Research }\end{array}$ & MRE \\
\hline 1411.72 & 704.05 & 0.50 & 1443.57 & 0.02 \\
\hline 2102.71 & 396.72 & 0.81 & 2394.93 & 0.14 \\
\hline \multicolumn{2}{r|}{ Mean } & 0.73 & Mean & 0.16 \\
\hline \multicolumn{2}{|c|}{ PRED(30) } & 0 & PRED(30) & 80 \\
\hline
\end{tabular}

Mehran University Research Journal of Engineering \& Technology, Volume 35, No. 4, October, 2016 [p-ISSN: 0254-7821, e-ISSN: 2413-7219] 
TABLE 17. ACCURACY COMPARISON FOR (ESCP) IN THIS STUDY

\begin{tabular}{|c|c|c|c|}
\hline \multirow{2}{*}{ CMM/CMMI Level } & \multicolumn{2}{|c|}{ MRE, PRED (30) } & \multirow{2}{*}{ Improvement (\%) } \\
\hline & COCOMO PA Model & This Research Model & \\
\hline \multicolumn{4}{|c|}{ EFFORT } \\
\hline Level 0 & $4.37,0$ & $0.28,57.14$ & 57.14 \\
\hline Level 1 & $3.40,0$ & $0.43,40$ & 40 \\
\hline Level 2 & $3.58,0$ & $0.15,100$ & 100 \\
\hline Level 3 & $0.37,66.67$ & $0.36,66.67$ & 0 \\
\hline Level 3, Organization B & $0.22,50$ & $0.21,50$ & 0 \\
\hline Level 3, Organization C & $0.32,50$ & $0.32,50$ & 0 \\
\hline Level 4 & $0.27,66.67$ & $0.27,66.67$ & 0 \\
\hline Level 5 & $2.31,33.33$ & $0.96,50$ & 16.67 \\
\hline \multicolumn{4}{|c|}{ TDEV } \\
\hline Level 0 & $0.36,64.29$ & $0.47,7.14$ & -57.15 \\
\hline Level 1 & $0.89,10$ & $0.56,10$ & 0 \\
\hline Level 2 & $0.97,0$ & $0.49,20$ & 20 \\
\hline Level 3 & $0.82,0$ & $0.35,25$ & 25 \\
\hline Level 3, Organization B & $0.45,0$ & $0.41,50$ & 50 \\
\hline Level 3, Organization C & $0.46,0$ & $0.40,50$ & 50 \\
\hline Level 4 & $0.92,0$ & $0.80,0$ & 0 \\
\hline Level 5 & $0.93,0$ & $0.93,0$ & 0 \\
\hline \multicolumn{4}{|c|}{ COST } \\
\hline Level 0 & $4.35,0$ & $0.23,64.29$ & 64.29 \\
\hline Level 1 & $3.40,0$ & $0.43,50$ & 40 \\
\hline Level 2 & $3.58,0$ & $0.15,100$ & 100 \\
\hline Level 3 & $0.41,50$ & $0.41,50$ & 0 \\
\hline Level 3, Organization B & $0.22,50$ & $0.21,50$ & 0 \\
\hline Level 3, Organization C & $0.32,50$ & $0.26,50$ & 0 \\
\hline Level 4 & $0.90,0$ & $0.89,66.67$ & 66.67 \\
\hline Level 5 & $0.82,0$ & $0.90,0$ & 0 \\
\hline \multicolumn{4}{|c|}{ PROD } \\
\hline Level 0 & $0.79,0$ & $0.35,85.71$ & 85.71 \\
\hline Level 1 & $0.74,0$ & $0.59,20$ & 20 \\
\hline Level 2 & $0.73,0$ & $0.16,80$ & 80 \\
\hline Level 3 & $0.45,50$ & $0.54,50$ & 0 \\
\hline Level 3, Organization B & $0.43,50$ & $0.27,50$ & 0 \\
\hline Level 3, Organization C & $0.17,50$ & $0.23,50$ & 0 \\
\hline Level 4 & $0.31,66.67$ & $0.26,66.67$ & 0 \\
\hline Level 5 & $0.56,41.67$ & $0.52,41.67$ & 0 \\
\hline
\end{tabular}


Another threat is that researchers cannot draw a general conclusion based solely on the results of this study because, a limitation exists on data ranges of variables and that projects were only related to MIS and Business applications. Therefore, it applies restriction on generalization of this research to other application domains. As it was not possible for the collected sample to cover a whole range of data values, it will not be realistic to assume that the results will be always generalized outside the settings in which the study was conducted. In order to include other possibilities of project type and size, one has to replicate this study for more projects with different sizes implemented using different SDPI levels.

\section{RESULTS AND DISCUSSION}

Section 4 has presented the interpretation of the benefits results in three participating organizations with data from sixty-two projects. We are discussing here the meaning and impact of result including the comments of the senior quality assurance personnel at data collection sites over unusual results.

Project data was collected for those past projects which were developed during the validity time period of their company's specific SDPI certification. Therefore, the SDPI

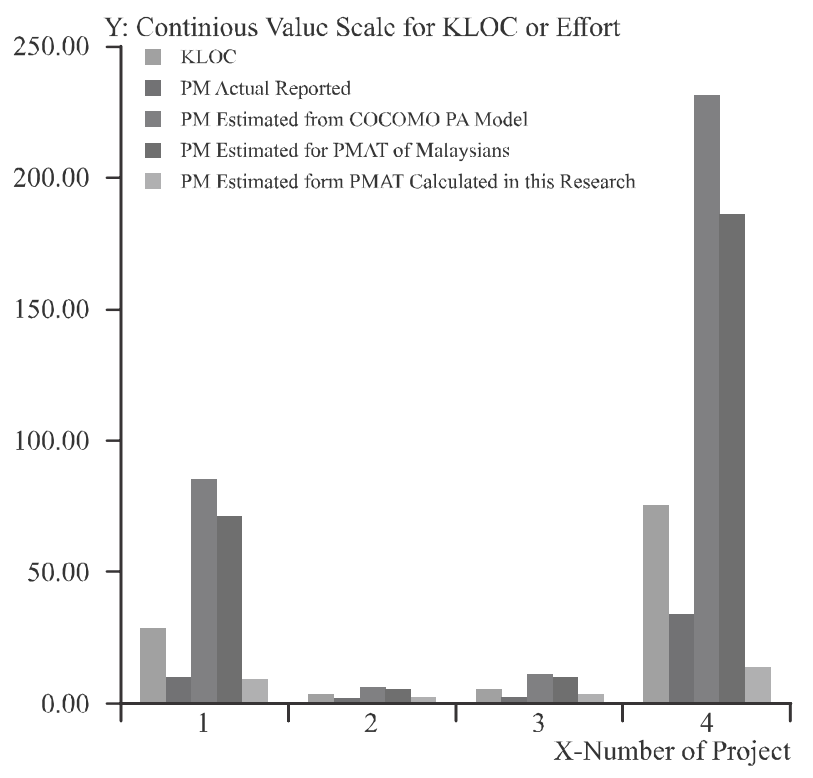

level was taken as the company's maturity level and not of the project itself. It was not useful to study projects which have already participated in appraisals. The projects which were part of the appraisal have to show aggregate benefits especially while appraising ML level 4 and 5 . It has been observed by the experts that to achieve appraisal ratings many companies produce fabricated records at a higher level.

In this research we have successfully devised a good mechanism to come up with a Prediction model which is not only proven reliable among research and professional communities but, it also has a very good prediction accuracy. The COCOMO-II Post Architecture model with ISF Ideal Scale Factor method has been implemented in this research, to tune it for reflecting CMMI base Process Maturity PMAT impact on software development project data, which is then taken as a benefit prediction model for CMMI. One major reason of adopting this method was the non-normal behavior of the collected dataset, otherwise we could also build upon a new regression base model on our collected data.

The result of this study shows that the mean-variance obtained from this research's "New model" with updated coefficient value for CMMI base Process Maturity variable PMAT is not the same as the mean-variance value obtained

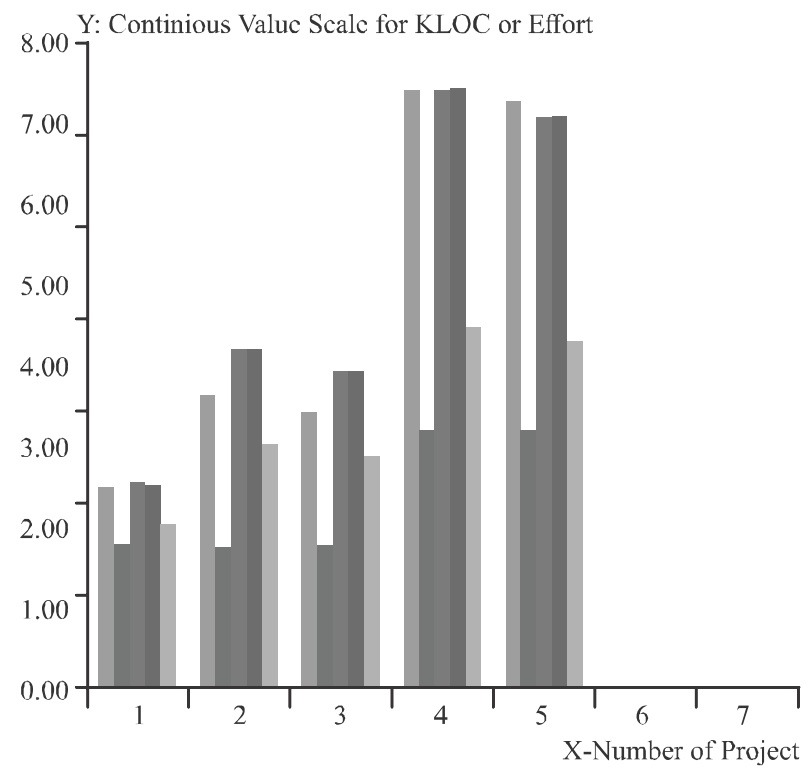

FIG. 5: ACTUAL EFFORT, COCOMO ESTIMATED, MALAYSIAN MODEL ESTIMATED AND THIS RESEARCH'S MODEL ESTIMATED EFFORT FOR CMMI ORGANIZATIONS A) AT LEVEL 0 B) AT LEVEL 5.

Mehran University Research Journal of Engineering \& Technology, Volume 35, No. 4, October, 2016 [p-ISSN: 0254-7821, e-ISSN: 2413-7219] 
from Constructive Cost model by Barry Bohem (COCOMOII)'s earlier values for CMM based process maturity and yields low variance. It found that with increasing levels of SDPI, not only Effort (PM) decreases but, the schedule and productivity value also decreases, whereas the project unit cost increases. This study also shows that in case of "Effort" during early years of SDPI adaptation, with every increasing level of SDPI adaptation of processes increases which consumes more time, effort, and man power. Another study [35] reports that in many cases of software project appraisals, the creation of evidence for appraisal, in order to justify a specific goal, takes much effort and added no value. The discussion with senior QA expert at data collection site has indicated that this increase reduces within a few years of implementing SDPI. This observation is purely the perception of QA manager and has not been empirically validated.

TABLE 18. SUMMARY OF HYPOTHESES RESULT FOR ANSWERING RESEARCH QUESTION-1

\begin{tabular}{|l|l|}
\hline \multicolumn{1}{|c|}{ Hypotheses } & $\begin{array}{c}\text { Supported or Not } \\
\text { Supported }\end{array}$ \\
\hline $\begin{array}{l}\text { H1: Increasing levels of SDPI gives more } \\
\text { accurate results for Effort estimation in this } \\
\text { research's model than original COCOMO } \\
\text { model. }\end{array}$ & \\
\cline { 1 - 1 } $\begin{array}{l}\text { H2: Increasing levels of SDPI gives more } \\
\text { accurate results for Schedule estimation in this } \\
\text { research's model than original COCOMO } \\
\text { model. }\end{array}$ & \\
\cline { 1 - 1 } $\begin{array}{l}\text { H3: Increasing levels of SDPI gives more } \\
\text { accurate results for Productivity estimation in } \\
\text { this research's model than original COCOMO } \\
\text { model. }\end{array}$ & \\
\cline { 1 - 1 } $\begin{array}{l}\text { H4: Increasing levels of SDPI gives more } \\
\text { accurate results for Cost estimation in this } \\
\text { research's model than original COCOMO } \\
\text { model. }\end{array}$ & \\
\hline
\end{tabular}

Fig. 5 has shown that this research's model gives close estimates of actual effort value as compared with the other two model estimates. This accuracy of estimation is common for all projects of CMMI level 0 through level 5. But here overall Effort estimation trend is different as compared to the COCOMO and Malaysian model's estimation trend, i.e. this research shows low consumption of effort in early stages of CMMI organizations which gradually increases till Maturity level 3 and again it drops down until it reaches ML5. Whereas the other two models produce high effort estimates in early levels of CMMI appraised organization and low efforts on the highest level of maturity organizations.

One major reason of this different behavior of Effort consumption is the unavailability of proper and low-cost process improvement tools to Pakistani software development companies [7-9]. If we look at TOOL (Table 2 for detail) effort multiplier settings at various Maturity level projects it also shows Low to Nominal level rating for all ML projects. Only one organization has afforded using very high to extra-high level TOOL ratings at maturity level 3. If we take a close look at Process Areas of CMMI versus the Process Areas of old CMM framework then two aspects are quite visible: (1) that CMMI level 2 has only one additional process area whereas the ML- 3 has around 7 additional process areas to follow, whereas, Level 4 and 5 have more or less the same process area. (2) these process areas requires added tool support and as discussed above the organizations hardly cross the usage of a basic front end, back end, and case tools with only minor integration. The above two aspects clearly justifies the reason of different effort consumption till ML 3 and a huge difference in magnitudes of original COCOMO model's PMAT value which is for old CMM framework used in international market and this research's ISF-PMAT value which is used in Pakistani working environment.

TABLE 19. PREDICTION ACCURACY COMPARISON FOR EFFORT MODEL USING IEM AND ISF FORMULA FOR

\begin{tabular}{|c|c|c|c|c|c|c|c|}
\hline PMAT Level & $\begin{array}{c}\text { ISF 1 Value using } \\
\text { IEM research }\end{array}$ & MRE & $\begin{array}{c}\text { PRED } \\
(30)\end{array}$ & $\begin{array}{c}\text { ISF 2 Value of } \\
\text { this research }\end{array}$ & MRE & $\begin{array}{c}\text { PRED } \\
(30)\end{array}$ & $\begin{array}{c}\text { Improvement } \\
(\%)\end{array}$ \\
\hline 0 & 1.27 & 3.34 & 0 & -46.50 & 0.28 & 57.14 & 57.14 \\
\hline 1 & 1.17 & 2.83 & 0 & -58.66 & 0.43 & 40 & 40 \\
\hline 2 & 1.14 & 3.08 & 0 & -46.82 & 0.15 & 100 & 100 \\
\hline 3 & 1.07 & 0.36 & 50 & -1.88 & 0.36 & 66.67 & 16.67 \\
\hline 4 & 1.05 & 0.27 & 66.67 & 11.36 & 0.25 & 66.67 & 0 \\
\hline 5 & 1 & 2.39 & 25 & -25.32 & 0.96 & 50 & 25 \\
\hline
\end{tabular}

Mehran University Research Journal of Engineering \& Technology, Volume 35, No. 4, October, 2016 [p-ISSN: 0254-7821, e-ISSN: 2413-7219] 
Our previous study [6] has also shown that, although, the rework value decreases about seven percent with the increasing levels of SDPI that should have caused a decrease in overall effort but the effort shows no decrease as it consumes more and more time in creating gold plating of QA documents without the proper help of genuine process management tools. In this research we have successfully devised a good mechanism to come up with a Prediction model which is not only proven reliable among research and professional communities but it also holds a very good prediction accuracy.

\section{CONCLUSIONS}

A project data of sixty-two dataset was used to enable COCOMO-II model for predicting benefit measurement classes ESCP in Pakistan. In COCOMO-II Post Architecture model the PMAT scale factor reflects the impact of CMM based process maturity on software development effort, therefore, in this research we have derived new PMAT value to reflect the impact of CMMI base process maturity for Pakistani software development environment.

The main contributions of this study includes the demonstration of a proper mechanism for deriving an SDPI benefits measurement "Prediction model" for non-normal and weak data set. MMRE, and PRED (N) measures have been used for comparing the prediction accuracy of estimated effort, schedule, cost, and productivity calculated from COCOMO-II model with the estimated values calculated from new prediction model. The results has shown that the meanvariance obtained from New model with updated ISF-PMAT value for CMMI Process Maturity variable is not same as the mean-variance value obtained from COCOMO II Post Architecture model's earlier values for CMM based process maturity and yields low variance.

\section{FUTURE WORK}

For future work in the area of SDPI prediction model development there is a need of more data collection from CMMI organizations and to apply local data set to tune or derive new PMAT rating levels for better prediction accuracy.

\section{ACKNOWLEDGEMENTS}

This research has been done with the permission of the representation bodies of Pakistan Software Industry, PASHA (Pakistan Software Houses Association) for Information Technology and PSEB (Pakistan Software Export Board). Authors appreciate the role of participant organizations for sharing their SDPI benefit related data. Authors also appreciate the role of our prestigious Institution "Hamdard University, Karachi" where this research has been conducted and to its respected staff, faculty, and management for their sincere support in achieving our goals. Then to our workplace "COMSATS University, Lahore" whose management particularly the Head of Department of Computer Science, has always supported us in sparing time for this lengthy and intense research work.

\section{REFERENCES}

[1] Saha, A., "SME Requires Different Approach. Management Innovation Exchange", 2010, (Available at www.managementexchange.com/hack/sme-requiresdifferent-approach-product-strategical-managementand-development-process-why) (Last Visit: December 7, 2010)

[2] Jarvis, A., and Crandall, V., "Inroads to Software Quality: How to Guide and Toolkit", Prentice-Hall, Inc., 1997.

[3] Kan, S.H., "Metrics and Models in Software Quality Engineering", 2 ${ }^{\text {nd }}$ Edition, Pearson Education, 2003.

[4] Melo, W., "Enhancing RUP for CMMI Compliance: A Methodological Approach. The Rational Edge", 2004, Available at www-106.ibm.com/developerworks/rational/ library/5318.html. (Last Visit: December 2012 )

[5] Schalken, J., Brinkkemper, S., and VanVliet, H., "Using Linear Regression Models to Analyse the Effect of Software Process Improvement", Product-Focused Software Process Improvement, pp. 234-248, Springer, Berlin Heidelberg, 2006.

[6] Hani, S.U., "Impact of Process Improvement on Software Development Predictions, for Measuring Software Development Project's Performance Benefits", Research Report, Hamdard University, Karachi Pakistan, 2015.

[7] Hassan, I., Qadri, S., Bashir, R.N., Saleem, R.M., and Naeem, M., "Issues of Implementation of CMMI in Pakistan Software Industry", International Journal of Innovation and Applied Studies, Volume 9, No. 2, pp. 547-564, 2014.

[8] The PSEB Group, "Market Assessment-2010", Technical Report, 2010, Available at www.pseb.org.pk/ images/study/pseb_it_market_review.pdf, (Last Visit: December 2012). 
[9] The PSEB Group, "Pakistan Software Industry Best Practices \& Strategic Challenges: An Exploratory Analysis", Ministry of Information and Technology, Government of Pakistan, Islamabad, 2005.

[10] Jones, C., "Early Sizing and Early Risk Analysis of Software Projects", Technical Report, Capers Jones \& Associates LLC, 2011, (Last Visit: September 26, 2011).

[11] Tamura, S., "Integrating CMMI and TSP/PSP: Using TSP Data to Create Process Performance Models", Technical Report No 33, Carneign Mellon University, Software Engineering Institute, Pittsburg, 2009.

[12] Walde, D., "Overview of a Business Case for CMMIBased Process Improvement", Presentation, General Dynamics: Advanced Information Systems, 2002.

[13] Bohem, B.W., "Software Cost Estimation with Contructive Cost Model 2000". Prentice Hall, New Jersey, 2000.

[14] Unterkalsteiner, M., Gorschek, T., Islam, A.K.M.M., Cheg, C.K., Permadi, R.B., and Feldt, R., "Extended Material to Evaluation and Measurement of Software Process Improvement - A Systematic Literature Review", 2010 .

[15] Hwang, S.M., "Process Quality Levels of ISO/IEC 15504, CMMI and K-Model", International Journal of Software Engineering and Its Applications, Volume 3, No. 1, pp. 33-42, 2009.

[16] Agrawal, M., and Chari, K., "Software Effort, Quality, and Cycle Time: A Study of CMM Level 5 Projects", IEEE Transactions on Software Engineering, Volume 33, No. 3, pp. 145-156, 2007.

[17] Lagerström, R., vonWürtemberg, L.M., Holm, H., and Luczak, O., "Identifying Factors Affecting Software Development Cost and Productivity", Software Quality Journal, Volume 20, No. 2, pp. 395-417, 2012.

[18] Boehm, B., Abts, C., and Chulani, S., "Software Development Cost Estimation Approaches-A Survey", Annals of Software Engineering, Volume 10, Nos. 1-4, pp. 177-205, 2000

[19] Hani, S.U., Imam, M., and Memon, G.Q., "Standardization of Software Cost Estimation Process for Outsourcing in Pakistan, Statistical Methods used for Checking Method Accuracy", International Conference of WORLDCOMP, Software Engineering Research and Practice, Las Vegas, USA, 2008.

[20] SD Process Canada, 2004, Available at www.stsc.hill.af.mil/ crosstalk/2002/03/diaz.html, (Last Visit: 2012).

[21] Chulani, S., Boehm, B.W., and Clark, B.K., "Calibrating the COCOMO II Post-Architecture Model", Proceedings of IEEE on ICSE, Volume 1, pp. 477-480, 1997.

[22] Chulani, S., Boehm, B.W., and Steece, B., "Bayesian Analysis of Empirical Software Engineering Cost Models", IEEE Transactions on Software Engineering, Volume 25, No. 4, pp. 573-583, 1999.
[23] Menzies, T., Chen, D.Z., Hihn, J., and Stakes. S., "Validation Method for Calibrating Software Effort Models", ICSE, 2005.

[24] Yang, Y., and Clark, B., "Reducing Local Calibration Bias in COCOMO II Calibration", 19th International Forum on COCOMO and Software Cost Modeling, 2004.

[25] Bohem, B.W., "Software Engineering Estimation", Prentice Hall, New Jersey, 1981.

[26] Al-Yahya, M., Ahmad, R., and Lee, S., "Impact of CMMI Based Software Process Maturity on COCOMO II's Effort Estimation", International Arab Journal of Information Technology, Volume 7, No.2, pp. 129-137, 2010.

[27] Hole, G., "Teaching Resources for Research Skills One", 2013, Available at http://www.sussex.ac.uk/Users/ grahamh/RM1web/teaching08-RS.html, (Last Visit: 2013).

[28] Gibson, D.L., Goldenson, D.R., and Kost, K., "Performance Results of Using CMMI Based Process Improvement", Technical Report, Software Engineering Institute, Carneign Mellon University, Pittsburg, 2006.

[29] The DACS Group, "DACS Tools: ROI Dash Board, Results for CMMI Process Improvement", 2010, Available at www.thedacs.com/databases/roi/roi_results.php? improvement $\% 5 \mathrm{~B} \% 5 \mathrm{D}=\mathrm{CMMI}+$ Process + Improvement $\&$ postback $=1 \& d a t a s e t=R O I \&$ chart_type $=$ text \&Submit=Submit, (Last Visit: 2010 ).

[30] The DACS Group, "Fact Information: on Benefits of CMMI Base SPI", 2011, Available at www.thedacs.com, (Last Visit: 2011).

[31] Chulani, S., and Bohem, B.W., "COCOMO-II and COQUALMO Questionnaire", 1999. Available at http:/ /csse.usc.edu/csse/research/COCOMOII/Docs/ cform22.pdf (Last Vist 2015).

[32] Nunnally, J.C., "Psychometric Theory", $2^{\text {nd }}$ Edition, McGraw-Hill, New York, USA, 1978.

[33] McGibbon, T., Ferens, D., and Vienneau, R.L., "A Business Case for Software Process Improvement (2007 Update) Measuring Return on Investment from Software Engineering and Management", DACS, Griffiss AFB, New York, USA, 2007.

[34] Mendes, E., "Software Measurement: How do You Plan to Measure? Surveys, Case Studies, Formal Experiments, Post-Mortem Analysis", Department of Computer Science, UoA, 2012, Available at www.cs.auckland.ac.nz/ compsci702s1c, (Last Visit: 2012).

[35] Garzas, J., and Paulk, M.C., "A Case Study of Software Process Improvement with CMMI-DEV and Scrum in Spanish Companies". Journal of Software Evolution and Process, Volume 25, No. 12, pp. 1325-1333, 2013. 